PREPRINT

AS54

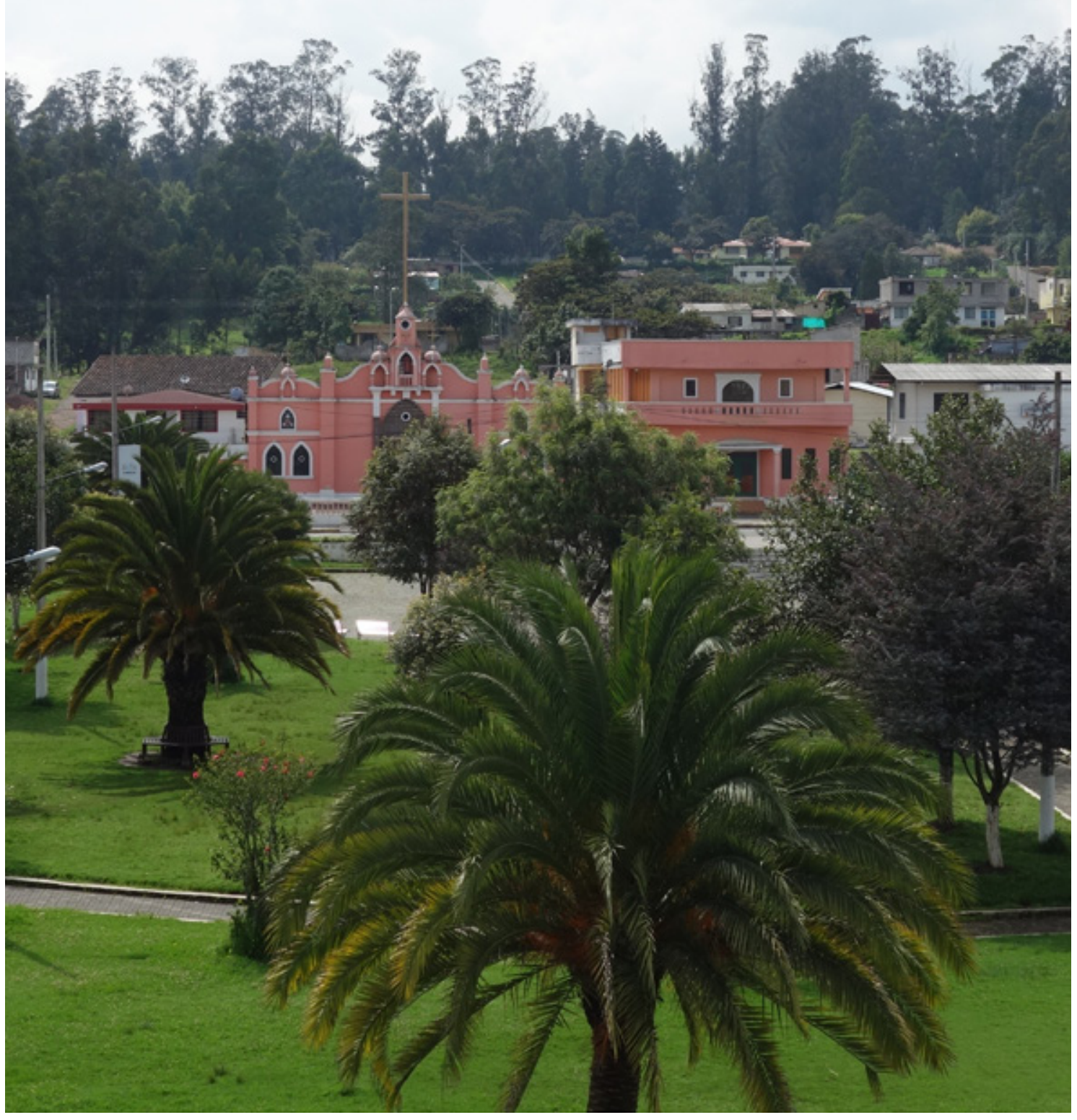

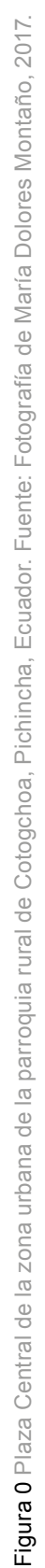



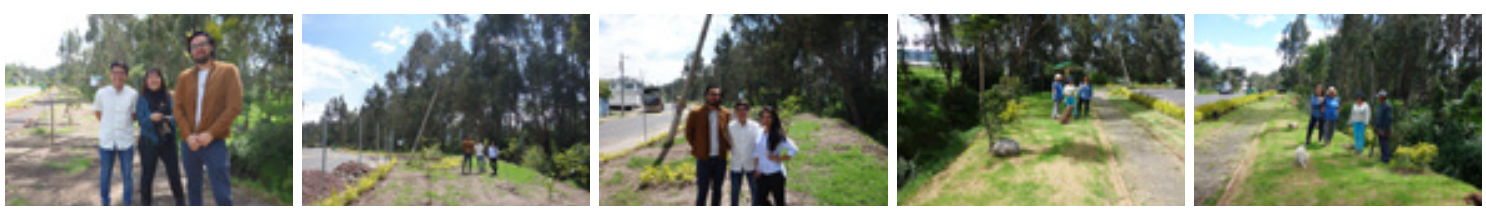

Secuencia: Seguimiento del proceso de Recuperación de la Quebrada Suruhuayco en Cotogchoa, Pichinch, Ecuador Fotos: María Dolores Montaño y Pamela Guerrón

\title{
RECUPERACIÓN DE LA QUEBRADA SURUHUAYCO, COTOGCHOA, ECUADOR, A PARTIR DE LA PROPUESTA DE "CRIANZA DE LOS PAISAJES VIVOS"1
}

\author{
RECOVERY OF QUEBRADA SURUHUAYCO, COTOGCHOA, PICHINCHA, ECUADOR, \\ FROM THE PROPOSAL OF "RAISING LIVING LANDSCAPES"1
}

\section{María Dolores Montaño Huerta²}

\section{RESUMEN}

Este documento muestra el proceso de recuperación de la quebrada Suruhuayco en la parroquia rural Cotogchoa, Pichincha, como un ejemplo de proyectos participativos desarrollados en comunidades vulnerables de Ecuador a través de la propuesta de "crianza de paisajes vivos". El proceso y elaboración de este tipo de proyectos es forjado en el Laboratorio de los Paisajes Vivos, FADA-PUCE, con investigadores, docentes y estudiantes vinculados con comunidades. La aquí presentada es una de las diversas propuestas que buscan el reconocimiento de las necesidades y carencias locales para la transformación participativa de sitios degradados, "paisajes malcriados", en "paisajes sanos", a través de acciones de concientización, diseño, concreción y cuidado de espacios que propendan a incentivar vínculos, afectos, comunicación y relaciones entre la comunidad. Así, este artículo expone metodologías, reflexiones y acciones que refuerzan, recuperan o desechan procesos; instancias y buenas prácticas, desde la academia hacia el mejoramiento de la calidad de vida de la comunidad.

Palabras clave: recuperación, diseño participativo, criar paisajes vivos, proyectos con la comunidad.

\section{ABSTRACT}

This document shows the process of recovery of the Quebrada Suruhuayco in the rural parish Cotogchoa, Pichincha, as an example of participatory projects developed in vulnerable communities of Ecuador through the proposal of "raising Living Landscapes". The process and elaboration of this type of project is forged in the Laboratory of Living Landscapes, FADA-PUCE, with researchers, teachers and students linked to communities. The presented here is one of the diverse proposals that seek the recognition of local needs and deficiencies for the participatory transformation of degraded sites, "spoiled landscapes", in "healthy landscapes", through awareness, design, concretion and care actions of spaces that tend to encourage bonds, affection, communication and relationships between the community. Thus, this article exposes methodologies, reflections and actions that reinforce recover or reject processes; instances and good practices, from the academy towards the improvement of the quality of life of the community.

Keywords: recovery, participatory design, raising living landscapes, projects with the community. 
La recuperación de la Quebrada Suruhuayco es uno de los múltiples proyectos que el Laboratorio de los Paisajes Vivos está emprendiendo con las comunidades. El laboratorio es un proyecto de investigación de la FADA-PUCE que nació en 2013 y que actualmente está en proceso de convertirse en espacio de investigación y centro de servicios. En él se integran tres elementos fundamentales: Docencia, Investigación y Vinculación con la comunidad. Se instaura a través del trabajo directo y participativo con comunidades vulnerables del contexto para la comprensión de la igualdad de derechos y la diversidad de expresiones y acciones de la comunidad. Le interesa profundizar las relaciones entre lo teórico, lo real, lo político y la práctica (Montaño, 2017: 35).

Esta instancia aborda las problemáticas para el soporte y trabajo con las comunidades y su hábitat desde la perspectiva de "paisajes vivos", basada en el hecho de que el ámbito en cuestión -el contexto andino- conserva raíces culturales ancestrales con características propias. A través de análisis y procesos de concientización, propios de este enfoque, se podrá comprender problemáticas y necesidades de la comunidad para guiar el diseño y la elaboración de proyectos: realización de acciones sensibles, consensuadas y participativas que mejoren el hábitat cotidiano de aquellos que viven en el territorio.

El proyecto para la recuperación de la Quebrada Suruhuayco pretende, precisamente, ejemplificar mediante su proceso lo que significa "criar paisajes vivos sanos".

\section{Los Paisajes Vivos}

Para entender la mirada desde la cual se trabaja en la recuperación de la Quebrada Suruhuayco, y de otras acciones académicas del laboratorio, se acude al estudio de la Filosofía Andina, de Josef Estermann (2006), quien a través de sus investigaciones en el mundo andino, establece la existencia de una filosofía andina contextual de tipo cultural, étnico y religioso. El pensamiento filosófico andino es distinto de la tradición occidental dominante y posee una visión intercultural que continúa existiendo en el presente en los contextos andinos de Sudamérica, hasta el norte de Argentina, y se expresa a través de un conjunto de costumbres, ritos, principios, éticas y modos de vivir (ibídem). Lo pertinente de la investigación sobre la filosofía andina para las acciones del laboratorio es la existencia de ese "modo de vivir andino" en el presente que, a diferencia de la cultura occidental, segregativa y excluyente, es intercultural. EI concepto "pacha" define todo lo existente en el universo: la "realidad" en la que se incluye la naturaleza y los seres humanos, denominados "runas".

El cosmos de los "andinos", en términos geográficos y topográficos, corresponde a aquellas regiones montañosas de Sudamérica situadas entre los 2.000 y los 6.900 metros de altura, pobladas hasta los 4800 metros y poseedoras de lenguas comunes, como el quechua, el aymara y español. En ellas se desarrollan gran variedad de culturas históricas, con experiencias artísticas locales y formas de organización peculiares. Es ahí donde habita el "hombre andino" o el "pueblo andino" (Sobrevilla, 2008). 
Los investigadores integrantes del Laboratorio de los Paisajes Vivos, localizado en Quito, Ecuador, estimaron que los estudios citados eran pertinentes para desarrollar proyectos de vinculación con las comunidades, ya que el territorio se localiza en contexto andino, por su situación geográfica y topográfica, por la gran variedad cultural y celebrativa, por el idioma común y, sobre todo, por la existencia de saberes, conocimientos, prácticas y modos de vida que están expresados y sobreviven a través de la interculturalidad.

La interculturalidad implica asumir un pensamiento donde el respeto a las diferencias, la coexistencia de diversas racionalidades en lo analítico, dialéctico, fenomenológico, estructural y hermenéutico son fundamentales. La interculturalidad permite el movimiento entre la cultura occidental y las culturas ancestrales, en este caso, la andina, no como opuestas sino como complementarias. Posibilita reconocer, respetar y articular las diferencias culturales (Laboratorio Paisajes Vivos, blogspot PUCE, 2017).

La interculturalidad supone que no se desecha el conocimiento, que no se lo aísla ni se lo pierde, sino, por el contrario, todos los conocimientos culturales, patrimoniales, tecnológicos, actitudinales, son tomados en cuenta y enriquecen los procesos de planificación conjunta. El conocimiento de lo local y sus características es decisivo para actuar en consenso y para completar, y apoyar de manera respetuosa y afectiva el crecimiento integral del territorio y sus paisajes. Los procesos de planificación intercultural de los paisajes vivos son históricos, participativos, dialogantes, unificadores y armónicos.

Los paisajes vivos según Karina Borja (2012) manifiestan que la naturaleza y el espacio son animados e integran relaciones entre lo natural y lo construido con el entorno sociopolítico, económico y cultural. Si los paisajes son vivos, están en un proceso de co-crianza y son parte de los que los habitan, trabajan y descansan en ellos. Son hechos convivenciales, simbólicos e inseparables del runa (Montaño, 2017: 35).

En el pensamiento andino la relación afectiva con un ser vivo al que se debe cuidar y criar tiene otras implicaciones para los paisajes. Se trata de ideas que, en el contexto actual, trastocan las relaciones e interrelaciones tradicionales y de $\neg$ mandan, además de un cambio en la forma de pensar, un abordaje interdisciplinar, pues escapan a lo puntual (Borja, 2016: 283).

Desde la concepción de los paisajes vivos, son necesarios los vínculos integradores que relacionan al ser humano y su entorno natural y construido, sin hacer diferencias jerárquicas entre todas las partes del sistema; siendo el runa también paisaje. Los paisajes somos todos y nos incluimos en ellos.

Bajo estas nociones de paisajes vivos que están en proceso de "crianza", las acciones de los proyectos se basan en actividades entretejidas e interdisciplinarias en los cuales las relaciones de afecto y de respeto entre paisajes son necesarias para el emprendimiento de iniciativas con las comunidades en las que se trabaja. El proyecto de recuperación de la Quebrada Suruhuayco se enmarca en conceptualizaciones, acciones de diseño y concreción participativa para lograr que la comunidad tenga un espacio vivo, de uso recreativo, que refuerce actividades sociales de fortalecimiento de vínculos y relaciones entre paisajes.

La propuesta de "crianza de paisajes vivos" -"uyway" en kichwa- significa intervenir en los paisajes como se cría a los hijos, a los animalitos, a la tierra: con afecto, cariño, respeto y libertad. Y eso se lo realiza comunitariamente, dialogando y consensuando. La crianza de paisajes es un concepto, una actitud, un proceso y una práctica aplicable a la elaboración de proyectos vinculados con las comunidades, en especial, las más vulnerables.

En este documento se expone el proceso de crianza de los paisajes de la Quebrada Suruhuayco, como un ejemplo para analizar, evaluar, confirmar o desechar acciones que enriquecen las buenas prácticas de vinculación con las comunidades andinas y que transmiten una mirada alternativa y valiosa de la planificación contemporánea.

\section{La importancia de la rehabilitación de las quebradas en contextos andinos}

Ecuador es atravesado de norte a sur por la cordillera de Los Andes con niveles entre $1.800 \mathrm{~m}$ a $6.310 \mathrm{msnm}^{3}$. El callejón interandino ecuatorial -debido a estas irregularidades geográficas y topográficas- se caracteriza por variadas condiciones climatológicas, físicas, de fauna y flora, pisos ecológicos y actividades humanas de extensa biodiversidad ${ }^{4}$. Los datos aludidos se han establecido en los sistemas nacionales del Ecuador ${ }^{5}$.

Ahora bien, como se ha definido que Ecuador está ubicado en un contexto andino, se considera que la pacha es la base común de los distintos estratos de la realidad local en la que se sitúa el territorio. Para el runa (persona humana), la pacha está constituida por tres estratos: hanaq pacha, kay pacha y uray (o ukhu) pacha, interrelacionadas entre el micro y el macrocosmos. Los cuerpos celestes, las estaciones, la circulación del agua, los fenómenos climáticos y lo divino tienen su correspondencia en el ser humano y sus relaciones económicas, sociales y culturales. El nexo entre el micro y macrocosmos es simbólico-representativo. Por tanto, los fenómenos de transición -que son chakanas o puentes cósmicos-, como los cerros, las nubes, el arcoíris, los manantes, los solsticios y los cambios de luna, tienen un carácter luminoso y sagrado. El ser humano representa mediante actos simbólicos lo que pasa en el espacio macro, asegurándose de esta manera de la continuidad del universo y de la perduración del orden cósmico. La correspondencia rige, ante todo, entre las esferas del hanaq pacha ("espacio de arriba") y del kay pacha 

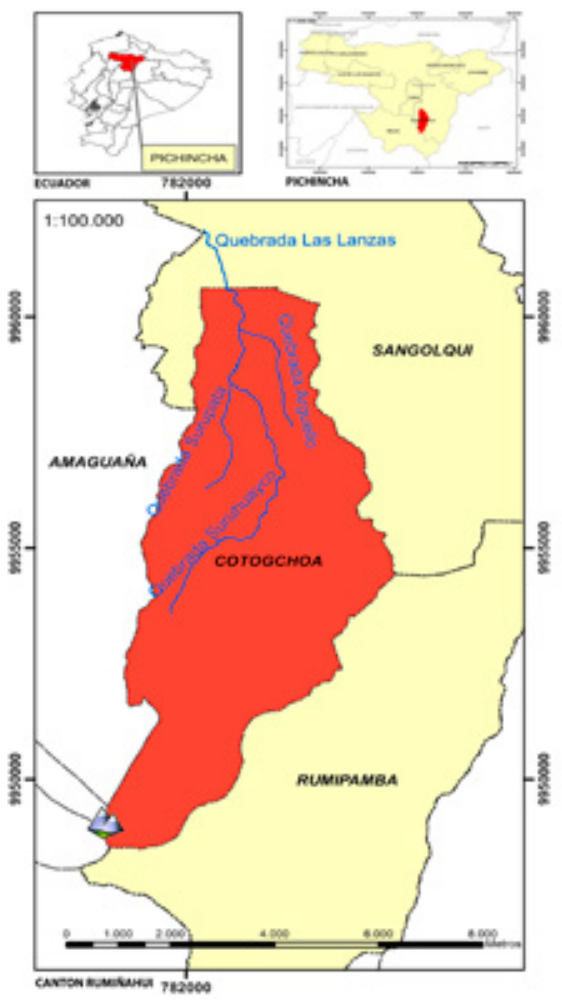

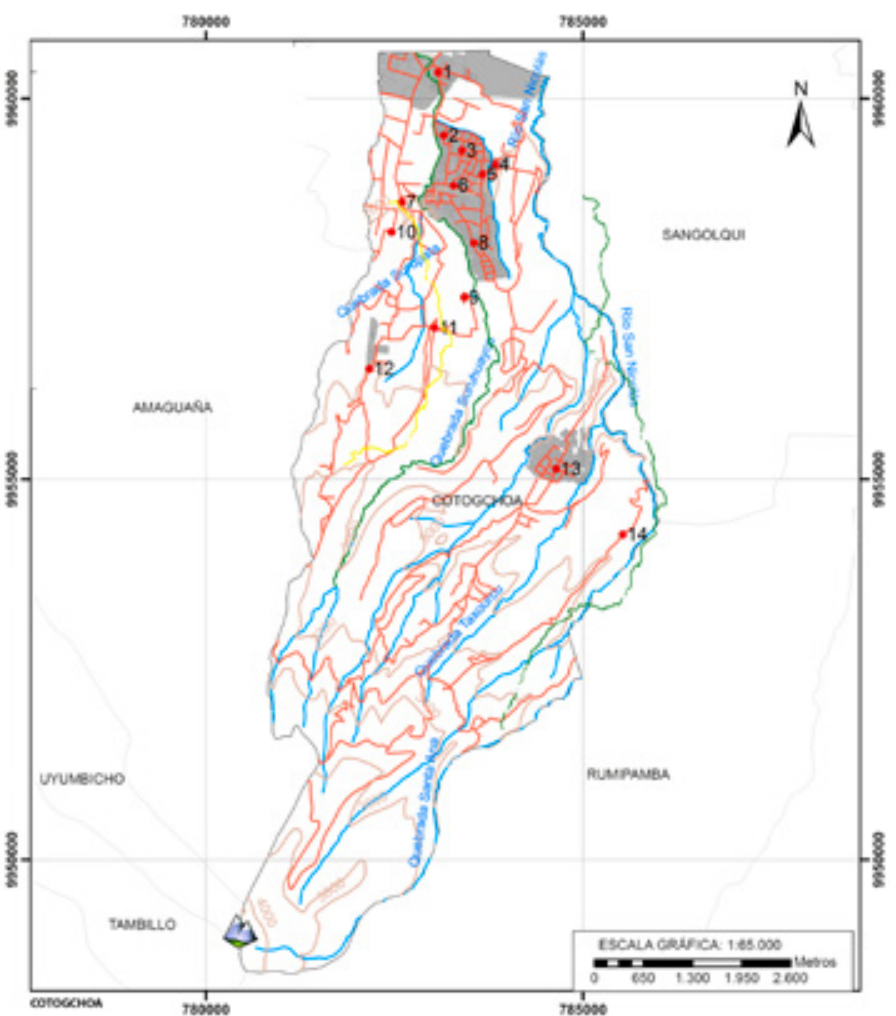

Figura 1 Ubicación de Cotogchoa y la Quebrada Suruhuayco en el contexto estudiado. Fuente: Elaboración de la autora.

("esfera de aquí y ahora"), mientras que la tercera esfera representa el mundo de "adentro", de los difuntos y ancestros (uray/ukhu pacha) (Estermann, 2006: 170-173).

En este contexto se ubican las quebradas en el territorio andino de Ecuador: depresiones entre montañas y nevados de diferentes profundidades y caudales de agua. Poseen una amplia diversidad de sistemas vivos, de fauna y flora silvestre que constituyen el 50\% de especies de plantas y animales nativos locales. Su funcionamiento adecuado garantiza la disminución de riesgos de deslizamientos y aluviones de lodo y agua. Son parte trascendental de los sistemas hídricos y ecológicos asociados a las cuencas hidrográficas de la sierra. Se constituyen en unidades ambientales básicas del territorio interandino. Facilitan la interrelación de unidades ecológicas de distintos pisos altitudinales. Los huaycos (su nombre kichwa) son considerados como los últimos reductos de vida silvestre del entorno andino ${ }^{6}$.

En tiempos ancestrales andinos, los pueblos originarios tenían una directa relación entre paisajes vivos y los vínculos con quebradas o huaycos eran continuos. Los unos dependían de los otros para convivir en paz y de ahí nacía el respeto a la vida natural de las quebradas y su entorno. Los huaycos correspondían al "ukhu Pacha" o mundo subterráneo: fuentes, caudales, acequias y cuevas. Estas quebradas o aperturas con el mundo subterráneo eran consideradas líneas de comunicación entre el ukhu pacha y el kay pacha, mundo de la tierra, del presente.

En entornos andinos como el de Quito y la provincia de Pichincha, los huaycos o quebradas, son espacios provistos de significados desde el pensamiento ancestral y la memoria, espacios de vida diversa, que han sido "malcriados" por efecto del descuido, la contaminación y los desechos. Las poblaciones les han dado la espalda $y$, actualmente, las quebradas son lugares inseguros, sucios, descuidados e ignorados.

Entonces, tanto desde la riqueza natural, así como de los significados valiosos que tienen, desde el pensamiento ancestral andino, las quebradas se constituyen lugares importantes, necesarios de ser rehabilitados, puestos en valor, en aras de devolverles su capacidad biótica y de establecer bordes, laderas y estancias como espacios propicios para la comunidad, para compartir y establecer relaciones y vínculos entre paisajes vivos -runas y naturaleza-. Se trata, en suma, de devolverle la capacidad de recuperación al paisaje característico y establecer proyectos ejemplificadores de convivencia y afectividad entre paisajes en hábitats andinos. 


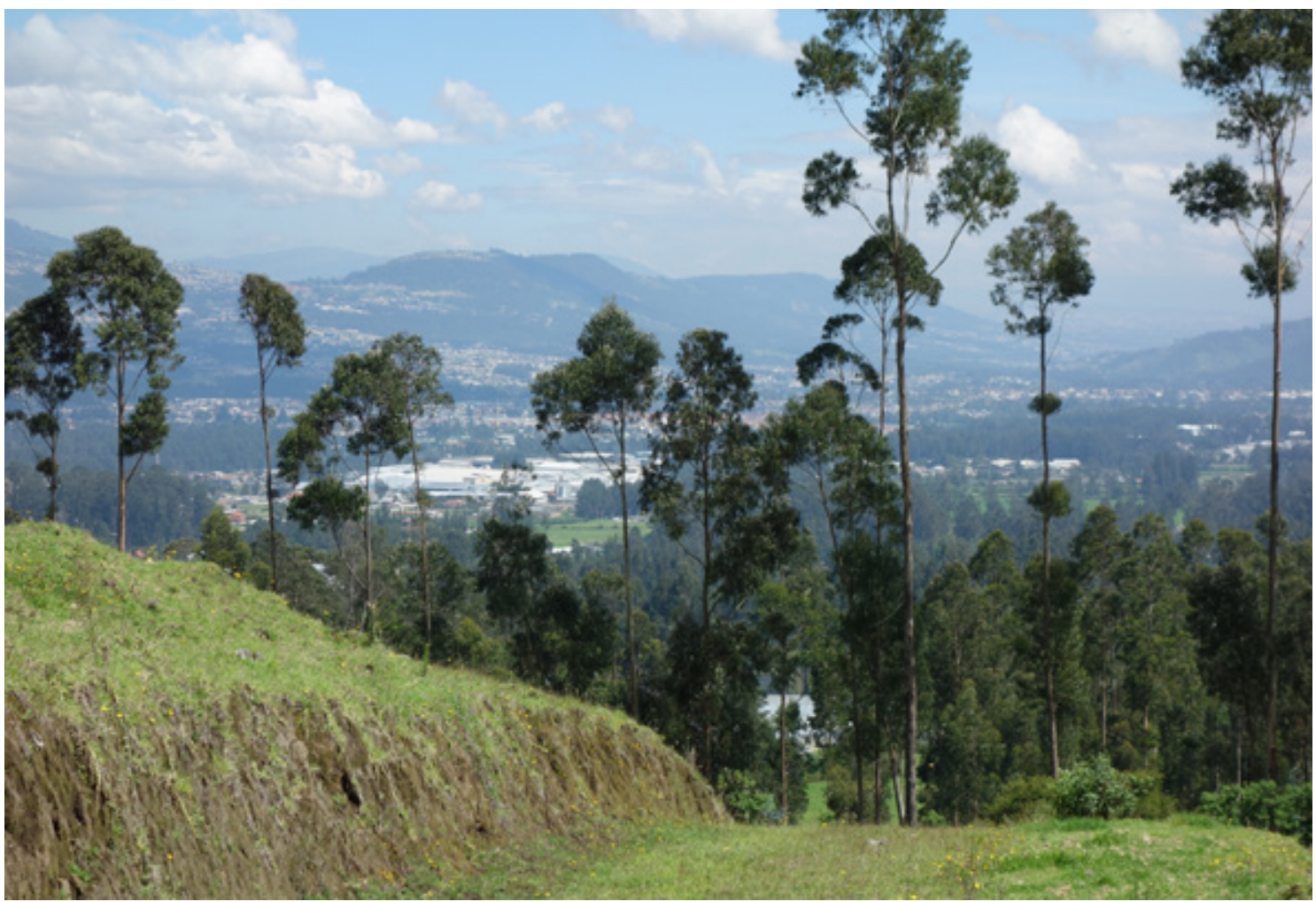

Figura 2 Vista de la zona urbana de Cotogchoa. Fuente: Fotografía de María Dolores Montaño, 2017.

\section{El contexto de Cotogchoa y la localización de la Quebrada Suruhuayco}

La parroquia rural de Cotogchoa, donde se ubica la Quebrada Suruhuayco, está situada a $41 \mathrm{Km}$ de Quito (Figura 1). Es un territorio topográficamente irregular, con la presencia de pisos o niveles que van desde los $2450 \mathrm{msnm}$-el acceso desde Quito- hasta los 4000 msnm, en el borde norte del Volcán Pasochoa. En cada nivel se registran actividades específicas propias de los territorios andinos con la biodiversidad característica de sus condiciones topográficas.

La memoria histórica de Cotogchoa (2018) refleja que los habitantes originales fueron huasipungueros o trabajadores de las haciendas como Cotogchoa y San Agustín. Desde aquellos tiempos, el cultivo del maíz forma parte de la vida productiva y cultural del lugar, así como el trigo, la cebada y las papas. La fiesta predominante en la hacienda era la Jacchigua, al final del ciclo de cosechas a través de las "mingas", un tipo de trabajo comunitario. Con la Reforma Agraria del año 1964, los latifundios se fraccionan y se entrega a los trabajadores agrícolas de las haciendas pequeñas extensiones de tierra en las que habían laborado ancestralmente. El significado de la tierra para los habitantes de Cotogchoa es muy importante, tanto para aquellos que se quedaron como para los que emigraron en búsqueda de nuevas posibilidades de vida. Muchos optaron por desarrollar otras ocupaciones, dejando atrás, en principio, el trabajo agrícola que habían realizado sus padres o ellos mismos en la niñez y juventud. Sin embargo, una forma simbólica de mantener un vínculo se expresa justamente en la tierra, a través de la conservación de parcelas, en una combinación de vivienda con la chacra para sembrar o criar algún animal. Desde la vida agrícola, la tierra representa una forma de pertenencia cultural, algo que se refleja también en la minga, en la fiesta a San Juan -el Santo Patrono de Cotogchoa-, al igual que en las fiestas de los patronos de cada barrio (Cifuentes y Borja, 2018: 14-24).

La tierra ha sido el elemento que ha dado lugar a que se conservara el valor identitario. Puede pensarse por ello en una forma híbrida de ruralidad al ser atravesado el sujeto por formas urbanas sin que desaparezca la fuerza viva de la tierra.

Los cambios de lugar y de ocupaciones han trastocado en las diferentes generaciones y han producido una heterogeneidad de vivencias y experiencias entre las familias de la comunidad. Pero, ¿qué los reafirma entre unos y otros? Los ritos y los valores en torno a la tierra. Los resultados de esta investigación fueron socializados en la comunidad. (Ibídem, 14-24)

Cotogchoa, por su accesibilidad a Quito se ha convertido en un borde de establecimiento de bodegas y complejos industriales en los lotes que originalmente eran haciendas agrícolas y ganaderas (Figura 2).

En el presente es un territorio ávido para el desarrollo de proyectos inmobiliarios y nuevas urbanizaciones en lotes rurales. Estos procesos, usuales de los desbordes urbanos de la ciudad, han puesto a la parroquia y a sus habitantes originarios en situación de vulnerabilidad, ya que está paulatinamente transformándose a actividades urbanas, lo que trae como efecto la migración 
diaria de los habitantes originales a plazas de trabajo en la ciudad, con la consecuente pérdida de antiguas formas de vida campesina, así como el deterioro de los valores originarios del sector: históricos, culturales, patrimoniales, memoria, actividades ancestrales, empleos y abastecimiento de recursos locales. Los paisajes vivos de Cotogchoa se ven afectados por este fenómeno que dificulta la accesibilidad a espacios comunes de comunicación, intercambio, festejos, recreación o encuentro de la comunidad.

La quebrada Suruhuayco es una corriente hídrica que ocupa el $41 \%$ del territorio de Cotogchoa y atraviesa el borde occidental de la zona urbana. La condición de deterioro de esta corriente se debe al vertido de aguas residuales y desagües que producen un espacio malogrado, de poco uso e inseguro para los habitantes de la zona, especialmente para los habitantes que se localizan al frente de sus bordes. Se le denomina entonces un paisaje "malcriado".

\section{MÉTODO}

La metodología utilizada en los procesos de diseño y concreción de la quebrada y de los proyectos del Laboratorio de los Paisajes Vivo es la investigación - acción - participación, que permite la retroalimentación continua entre la academia-comunidad.

La investigación-acción-participación, como lo expresa Bausela (2004), es:

\section{[...] un término acuñado y desarrollado por Kurt Lewin en varias de sus investigaciones (Lewin 1973: 135-174), actualmente, es utilizado con diversos enfoques y pers- pectivas, depende de la problemática a abordar. Es una forma de entender la enseñanza, no sólo de investigar sobre ella. La investigación - acción supone entender la enseñanza como un proceso de investigación, un pro- ceso de continua búsqueda. Conlleva entender el oficio docente, integrando la reflexión y el trabajo intelectual en el análisis de las experiencias que se realizan, como un elemento esencial de lo que constituye la propia actividad educativa. Los problemas guían la acción, pero lo fundamental en la investigación - acción es la exploración reflexiva que el profesional hace de su práctica, no tanto por su contribución a la resolución de problemas, como por su capacidad para que cada profe- sional reflexione sobre su propia práctica, la planifique y sea capaz de introducir mejoras progresivas. En general, la investigación - acción cooperativa constituye una vía de reflexiones sistemática sobre la práctica con el fin de optimizar los procesos de enseñanza - aprendizaje. (2004: 1)}

La investigación acción se basa en la organización de tareas grupales en continuo proceso de evaluación: planificación, acción, observación, reflexión, en distintos escenarios de trabajo. Las tareas de investigación requieren contextos sociales de intercambio, discusión y contrastación que permiten diálogos con otras voces y otros conocimientos (ibídem).

La labor abordada hacia la "crianza de los paisajes vivos" en la rehabilitación de la quebrada, recurre a la metodología de investigación-acción-participación para la retroalimentación de acciones y procesos en cualquiera de las fases. Esto se respalda en el principio andino de "ciclicidad", el cual concibe tiempo y espacio (pacho) como algo repetitivo. En efecto, debido a las actividades agrícolas, el hombre andino entiende el tiempo y espacio como fenómenos iterativos. El infinito está en movimiento circular, es un espiral interminable. Cada círculo describe un ciclo: las estaciones del año, la sucesión de las generaciones o las eras históricas. Lo nuevo como algo absolutamente desconocido no existe para el pensamiento andino (Estermann, 1998, cit. Montaño, 2017: 33).

En la propuesta metodológica aquí expuesta, este principio andino de ciclicidad es utilizado para la alimentación y retroalimentación de los procesos desde cualquier parte. Más concretamente,

La metodología está relacionada y referida a la investigación-acción participación, en la cual las acciones realizadas no son procesos lineales, sino que avanzan en espiral; son un hacer y deshacer al que se incorpora la experiencia, el conocimiento y la práctica. El proceso posibilita que todos los actores (paisajes) se sientan copartícipes y se empoderen de la construcción de un proyecto. Los procesos metodológicos se arman en espiral: hacer-deshacer-rehacer-empezar de nuevo, conjugándose con la concepción espacio temporal de la ciclicidad andina. La ciclicidad se comprende desde la actividad primigenia del territorio andino: la agricultura. La metodología se forja en coherencia con los ciclos de la vida. No es una línea continua sin fin, sino un movimiento espiral al cual se le podrán ir agregando cuestionamientos, parámetros, opiniones, criterios y seguimientos de ida y vuelta. Los procesos no son ni nuevos, ni irrepetibles, ni definitivos, sino que son procesos de crecimiento, de ir y volver, de inserción de elementos, y de la necesidad de desenvolverse y actuar en escenarios múltiples en vinculación directa con el territorio y sus paisajes. (Montaño, 2017: 68)

Así, la comunidad y su dimensión cultural es clave para el diagnóstico de necesidades, resolución de conflictos y propuestas que cultiven los paisajes y la identidad local.

A continuación, se integra el proceso metodológico que ha sido utilizado en el diseño participativo de la recuperación integral de la quebrada, tomando en cuenta que siempre se va trabajando en procesos de ida y vuelta, de inserción de elementos que surgen en los acontecimientos temporales y que son procesos espirales de hacer-deshacer-rehacer-empezar de nuevo, por lo cual estos no son ni acabados, ni permanentes (Tabla 1).

Como se ha señalado, el Laboratorio de paisajes vivos integra tres elementos fundamentales: Docencia, Investigación y Vinculación con la comunidad. El proceso metodológico de investigación-acción-participación que se explica ahora se enmarca en las acciones del laboratorio desde esas tres dimensiones.

La imagen, concepción y recopilación de información para la rehabilitación de la Quebrada Suruhuayco contaron con el soporte investigativo del Taller prepro- 


\begin{tabular}{|c|c|c|}
\hline \multicolumn{3}{|c|}{ PROCESO METODOLÓGICO DE LA QUEBRADA SURUHUAYCO } \\
\hline \multicolumn{3}{|c|}{ LABORATORIO DE LOS PAISAJES VIVOS } \\
\hline \multicolumn{3}{|c|}{ FADA-PUCE } \\
\hline ETAPAS & DETALLE & ACTIVIDADES \\
\hline 1 & $\begin{array}{l}\text { Conceptualizaciones de los paisajes vivos entre } \\
\text { investigadores, docentes y estudiantes }\end{array}$ & $\begin{array}{l}\text { Presentaciones, charlas, conferencias, diálogos, ejes importantes del } \\
\text { laboratorio }\end{array}$ \\
\hline 2 & Taller de arquitectura & \\
\hline 2.1. & $\begin{array}{l}\text { Investigación del territorio y sus paisajes a través de la } \\
\text { vinculación en escenario de Cotogchoa }\end{array}$ & $\begin{array}{l}\text { Visitas y sensibilización al territorio, sensibilización del espacio, partici- } \\
\text { pación con los miembros de la comunidad, valoración de los paisajes, } \\
\text { investigación de los deseos y actividades de la comunidad y descubrir que } \\
\text { proyectos enfrentar }\end{array}$ \\
\hline 2.2. & $\begin{array}{l}\text { Diagnóstico y valoración de la comunidad y sus } \\
\text { paisajes }\end{array}$ & $\begin{array}{l}\text { Generar un documento en presentación con los análisis y diagnósticos a } \\
\text { compartir con la comunidad }\end{array}$ \\
\hline 2.3. & $\begin{array}{l}\text { Planteamiento desde el taller de los proyectos nece- } \\
\text { sarios en consenso entre estudiantes y profesora }\end{array}$ & Generación de proyectos desde el taller \\
\hline 2.4. & $\begin{array}{l}\text { Presentación de los proyectos posibles a la comu- } \\
\text { nidad }\end{array}$ & $\begin{array}{l}\text { Presentación y toma de decisiones sobre los proyectos emprenderse desde } \\
\text { el taller de arquitectura }\end{array}$ \\
\hline 2.5. & $\begin{array}{l}\text { Desarrollo de proyectos semilla individuales decidi- } \\
\text { dos con la comunidad }\end{array}$ & $\begin{array}{l}\text { Desarrollo del proceso de diseño arquitectónico. Elaboración de proyectos: } \\
\text { plantas, cortes, implantaciones, fachadas, perspectivas, memorias }\end{array}$ \\
\hline 2.6. & $\begin{array}{l}\text { Presentación de los proyectos semilla más relevantes } \\
\text { y discusiones para poder concretarlos }\end{array}$ & $\begin{array}{l}\text { Decisiones conjuntas con la comunidad en la selección de proyectos priori- } \\
\text { tarios y los procedimientos para seguir: la Quebrada Suruhuayco }\end{array}$ \\
\hline 3 & $\begin{array}{l}\text { Vinculación con la comunidad laboratorios de los } \\
\text { paisajes vivos-puce }\end{array}$ & $\begin{array}{l}\text { Solicitud a la puce de parte de la comunidad para inscripción de proyectos } \\
\text { en Cotogchoa: Quebrada Suruhuayco }\end{array}$ \\
\hline 3.1. & $\begin{array}{l}\text { Asignación de profesor vinculador con la comunidad } \\
\text { y su equipo }\end{array}$ & Visita y presentación de nuevo grupo \\
\hline 3.2. & $\begin{array}{l}\text { Taller de diseño participativo 1: Imagen de la quebra- } \\
\text { da de parte de los integrantes de la comunidad }\end{array}$ & $\begin{array}{l}\text { Organización, elaboración de bocetos de la comunidad, establecimientos } \\
\text { de responsabilidades y plazos }\end{array}$ \\
\hline 3.3. & $\begin{array}{l}\text { Taller de diseño participativo 2: La imagen futura de } \\
\text { la quebrada }\end{array}$ & $\begin{array}{l}\text { Bocetos y sociabilización de la imagen futura. Definición de acciones } \\
\text { comunitarios en el emprendimiento de la recuperación de la quebrada }\end{array}$ \\
\hline 3.4. & Minga comunitaria para replanteo y siembra & $\begin{array}{l}\text { Equipo de vinculación realiza implantación de acuerdo a las imágenes } \\
\text { futuras del proyecto. Replanteo en sitio a través de minga comunitaria }\end{array}$ \\
\hline 3.5. & $\begin{array}{l}\text { Comunidad se apropia del territorio y se autoconvoca } \\
\text { para siguientes mingas }\end{array}$ & Mingas comunitarias: criar paisajes en el lugar \\
\hline 4 & $\begin{array}{l}\text { Entrega de proyecto de la quebrada a la comu- } \\
\text { nidad }\end{array}$ & Entrega a la comunidad del proyecto \\
\hline 5 & Seguimiento y sociabilización & \\
\hline 6 & $\begin{array}{l}\text { El gobierno autónomo descentralizado de la } \\
\text { parroquia contrata a un profesional para las obras } \\
\text { principales }\end{array}$ & Realización de obras prioritarias \\
\hline 7 & $\begin{array}{l}\text { Seguimiento, reflexiones sobre lo actuado, } \\
\text { difusión }\end{array}$ & Construcción teórica-práctica del proceso para enriquecer acciones futuras \\
\hline
\end{tabular}

Tabla 1 Proceso metodológico para la rehabilitación de la quebrada Suruhuayco, entre otros proyectos con la comunidad de Cotogchoa. Fuente: Elaboración de la autora

fesional de Arquitectura de la FADA que realiza la indagación y reconocimiento del territorio y sus paisajes a través de dos instancias: el examen sensorial de las condiciones de los paisajes vivos y las investigaciones geográficas, climáticas, físicas, estéticas, funcionales, políticas, culturales, históricas del territorio.

La siguiente etapa es la sociabilización del proyecto a través del grupo, profesora y estudiantes del Taller de arquitectura con integrantes de la comunidad, para realizar un análisis acerca de deseos, expectativas, lu- gares representativos, puntos de encuentro, necesidades y sueños. Con estos insumos se realiza la labor de síntesis y reconocimiento del territorio y sus paisajes, presentando luego la problemática a la comunidad en una labor de diálogo y acercamiento. A través de estas reuniones, los diversos actores, comunidad-academia, evalúan y reconocen los proyectos representativos. En la etapa siguiente, el Taller de arquitectura desarrolla proyectos "semillas", que aportan con ideas y respuestas en los diálogos y las demandas con la comunidad. En ese sentido, Armijos et al. detallan: 


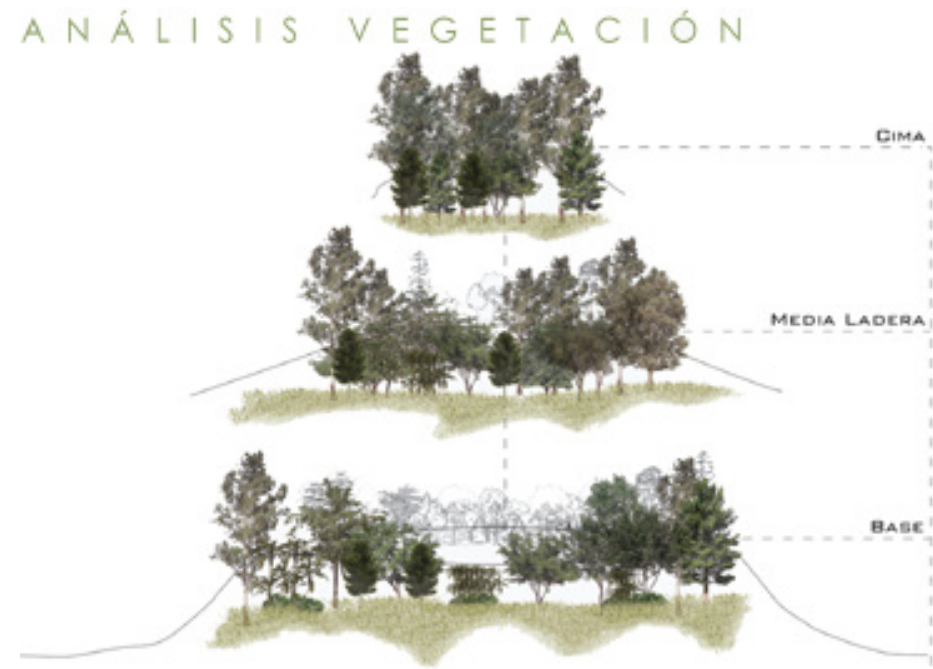

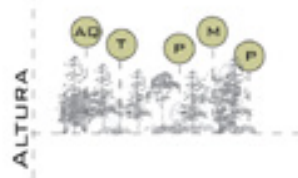

() 두우 (ㄷ)

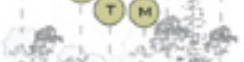

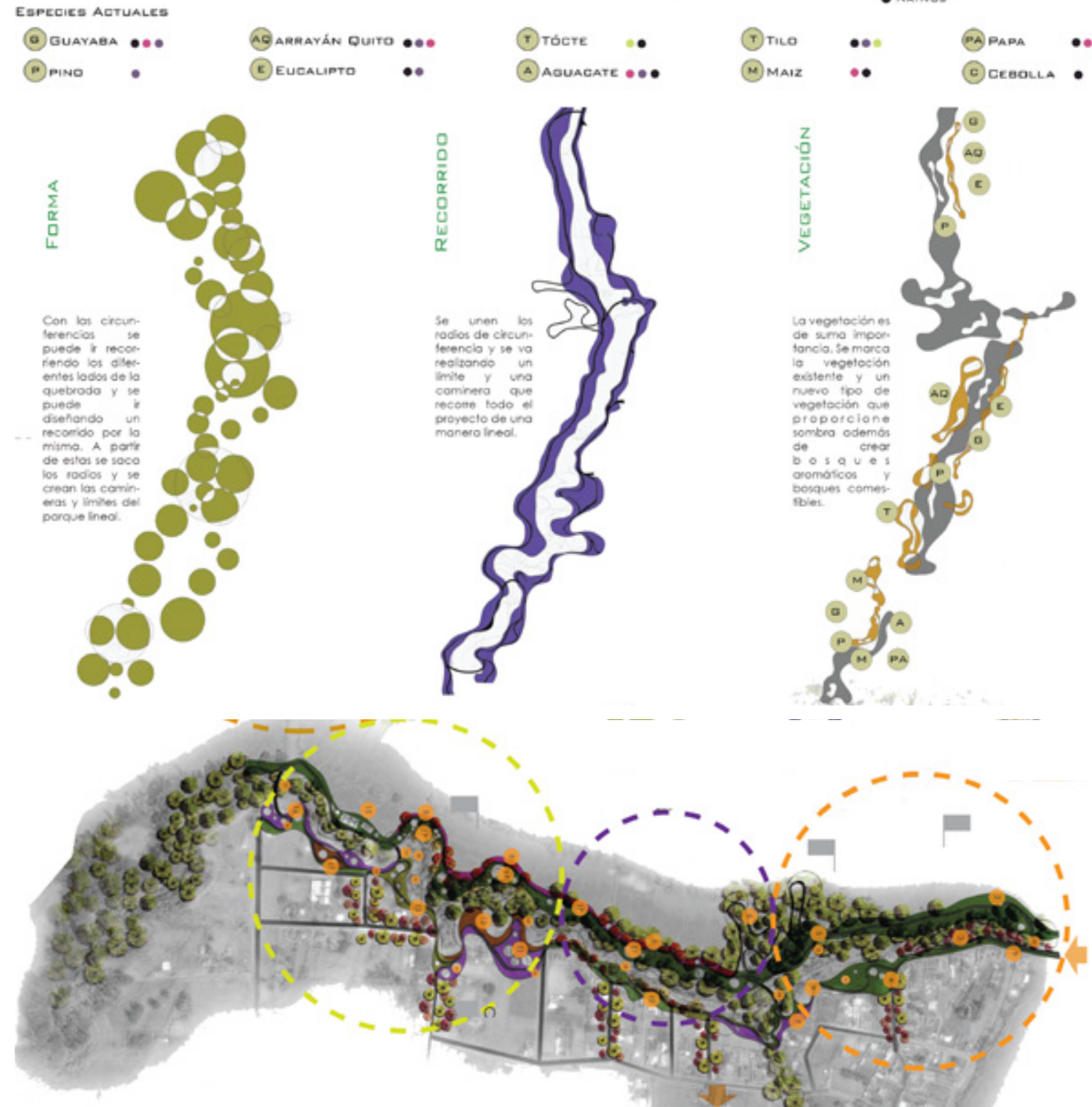

Figura 3 Estudio de forma, recorridos y vegetación: Quebrada Suruhuayco en tramo de 3000 metros. Fuente: Elaboración de Josué Vallejo, 2015 
Basados en las reflexiones de la docencia y las acciones de los estudiantes del Taller de Arquitectura, en esta etapa, los estudiantes y el profesor aprenden a escuchar los puntos de vista de los demás, adquieren conciencia de que su intervención debe ser respetuosa con la comunidad y sus paisajes, porque de ellos provienen las demandas y las necesidades. Son partícipes de acciones útiles, que se aproximan a los desafíos de lo real. Saben que no producen proyectos utópicos, inventados, sino que enfrentan las problemáticas en coherencia con el contexto y las condiciones locales. De esa manera, aceptan los retos sin prejuicios y aprenden a escuchar, a conocer otros puntos de vista, a comprender realidades que son distintas a las propias, a realizar proyectos que se auto soportan y a defenderlos de manera consensuada. Los estudiantes se sensibilizan, experimentan, son flexibles, aprenden a ser criticados, a ser permeables y a dar el salto en la concreción de proyectos con procesos de diseño engarzados a los vínculos con la comunidad y sus actores. Por su parte, la comunidad interactúa con estudiantes que con la guía del profesor comprenden sus demandas, reflexionan sobre las problemáticas y resuelven éstas mediante proyectos consensuados y comprendidos en participaciones y exposiciones. Se siente copartícipe del proceso y se enorgullece del reflejo de sus propias acciones participativas en el diseño. (2016: 121-122).

El siguiente paso consiste en la elaboración del anteproyecto arquitectónico desde el Taller de Arquitectura en diversos escenarios de trabajo a través de los insumos de comunicación, participación e interacción con la comunidad.

Al finalizar el semestre, se elige el proyecto que cumplió las expectativas generales de la comunidad como resultado del proceso de la investigación y demanda.
Se desarrollan documentos necesarios: planos, cortes, perspectivas y memorias que exponen la propuesta y reflejan cómo se utiliza el espacio para la comunicación, el respeto de las condiciones del lugar, el intercambio y el encuentro donde la comunidad se integre y participe a través de la comprensión de conceptos, condiciones y procesos basados en la crianza de paisajes vivos. Específicamente en este caso, el estudiante Josué Vallejo produjo un proyecto en un tramo de $3 \mathrm{~km}$ de quebrada, complejo y completo, sensible a las condiciones del lugar y al reconocimiento específico de la problemática. A partir del estudio de las demandas y sociabilización con la comunidad y del análisis físico de la forma, condiciones topográficas, vegetación y fauna, se elaboró el proyecto del espacio de borde de la quebrada: zonas de estar, paseos, caminos, teatro al aire libre, zonas de estancia y recorridos, acopio y comercialización, ligados a actividades residenciales, estudios de arborización y determinación de especies autóctonas en los bordes (Figura 3). Criar paisajes implica en esta propuesta integrar a la comunidad a un espacio público de interacción y actividades de comunicación y encuentro (Figura 4).

Con la elaboración de los "proyectos semillas" se procede a la exposición/entrega del proyecto a la comunidad. De tal modo, la iniciativa suscita interés y entendimiento; se lo reconoce como necesario y se comienza a canalizar acciones para que se concrete. Se elige un tramo de 100 metros de quebrada en el acceso a la parroquia, Barrio San Juan Obrero como proyecto piloto de recuperación.

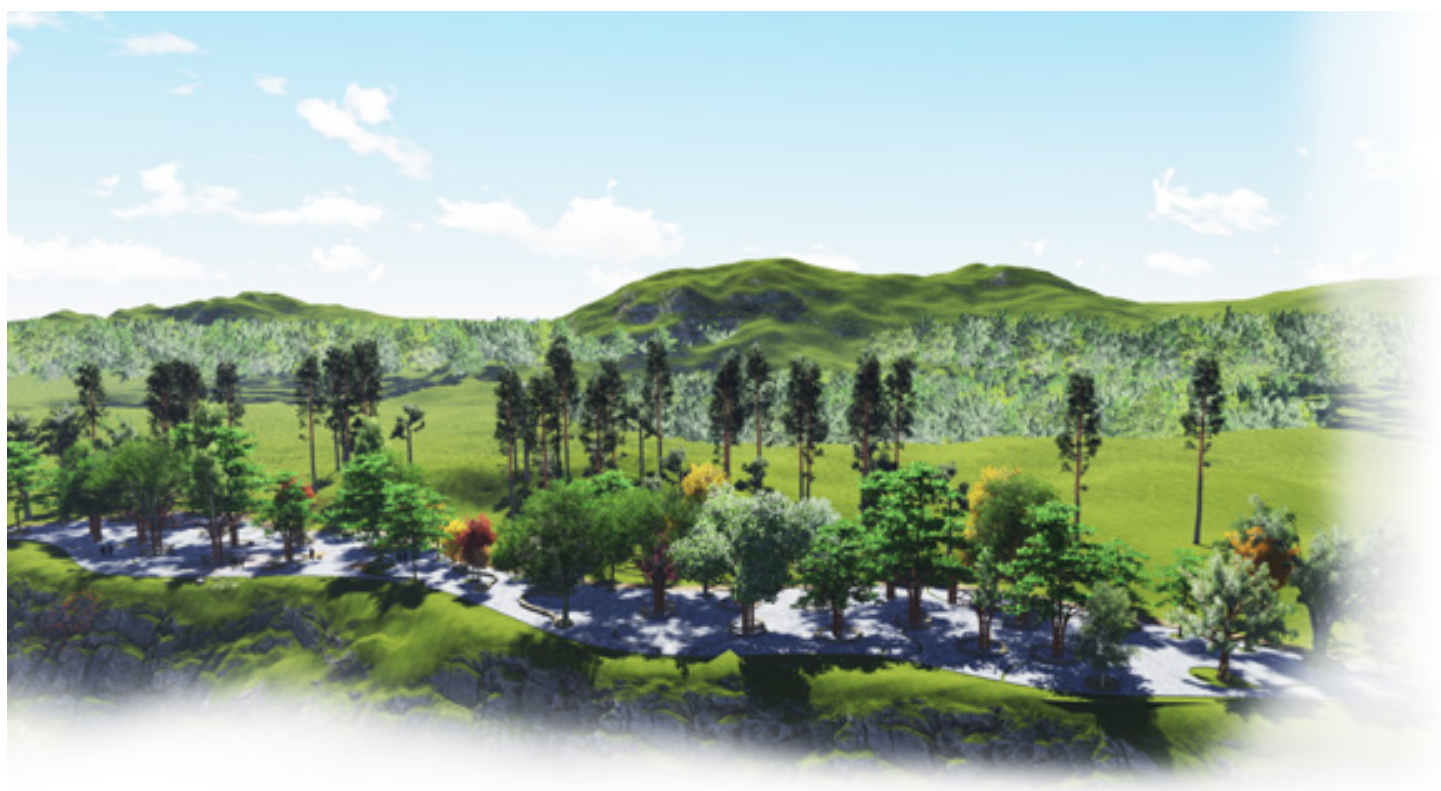

Figura 4 Perspectivas del proyecto semilla. Fuente: Elaboración de Josué Vallejo, 2015. 
El proyecto continúa en otra instancia del Laboratorio de los Paisajes Vivo: Vinculación con la Comunidad, a través de la creación de un nuevo equipo conformado por un profesor, un diseñador, un investigador y estudiantes de prácticas de Acción Social PUCE. El nuevo equipo sistematiza la información y documentación y se prepara para continuar con el diseño-participativo del proyecto de recuperación de la quebrada en condiciones reales y con terreno específico.

Con este nuevo grupo se realizan varias instancias y talleres de participación:

Un primer taller se sociabiliza, y en él se analizan y grafican las condiciones críticas de la quebrada, se organizan grupos de trabajo convocados para la elaboración de gráficos, metáforas y bocetos con memoria que reflejan el estado de deterioro del sitio, los principales puntos de contaminación y las problemáticas (Figura 5). Se establecen, así, responsabilidades a asumir en el proceso hacia un siguiente taller.

Se convoca, luego, al segundo taller de participación, en el que se elaboran sobre mapas los deseos y la propuesta de ocupación y uso de los espacios de la quebrada. Los diversos grupos participantes exponen sus proyectos. Se registran las evidencias y testimonios para la elaboración de planos proyectuales.

Se establece, entonces, la agenda para realizar la minga comunitaria, la cual se lleva a cabo con los planos elaborados a partir de los dos talleres para la ejecución de acciones necesarias: revisión de replanteo, limpieza y movimiento de tierras, peinado manual de la superficie, mediciones, colocación de estacas y siembra de árboles (Figura 5).

A partir de las actividades de replanteo y plantada de árboles, el gobierno de la parroquia, que dispone de una partida para la recuperación del espacio contrata la construcción de caminos, bordes y lugares de estancia y sociabilización. La FADA entrega estructuras de madera donadas por los estudiantes de Taller de Arquitectura de Nivel 1, que los carpinteros de la zona se encargarán posteriormente de utilizar para mobiliario urbano y lugares de sombra.

Con estas acciones de diseño y construcción participativa, la comunidad se autoconvocó en algunas ocasiones para seguir trabajando en el proyecto, oportunidades a las que el equipo académico no fue convocado. No obstante, esto fue considerado como parte de un proceso donde la comunidad se empodera y apropia de sus proyectos para autogestionarlos y finalizarlos.

En tiempo académico, con la minga termina el proceso de Acción Social PUCE y un nuevo grupo de estudiantes se integra al semestre siguiente y reelabora el proyecto, mientras la comunidad continúa las acciones de recuperación de la quebrada (Figura 6).

[7] Facultad de Arquitectura, Diseño y Artes. Pontificia Universidad Católica del Ecuador.

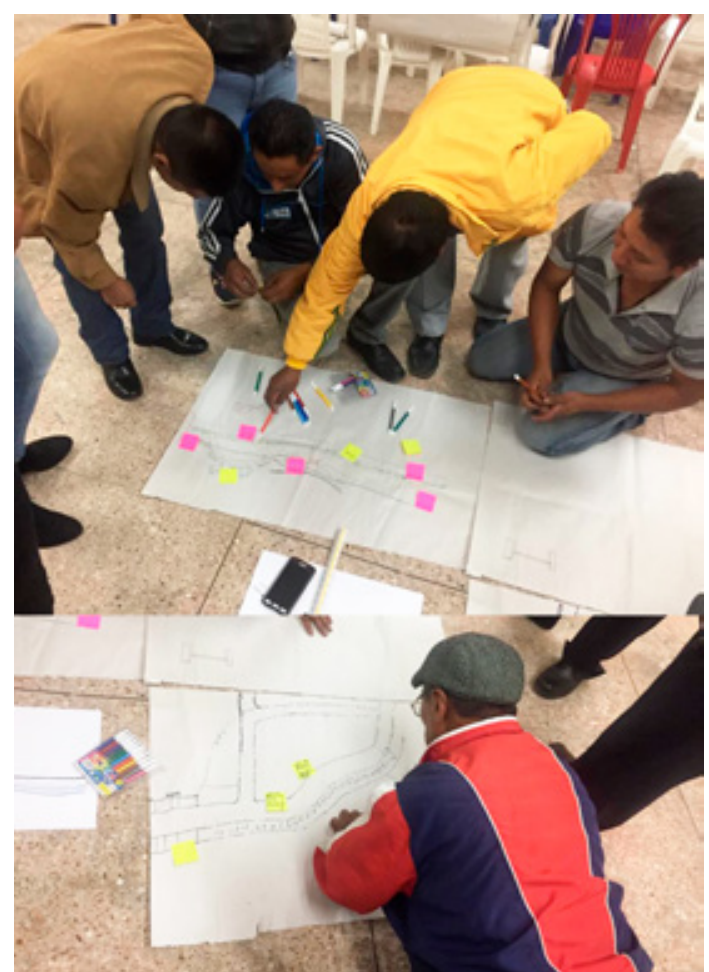

Figura 5 Cada grupo trabaja y expone las condiciones y las problemáticas de la Quebrada. Fuente: Fotografías de María Dolores Montaño, 2017

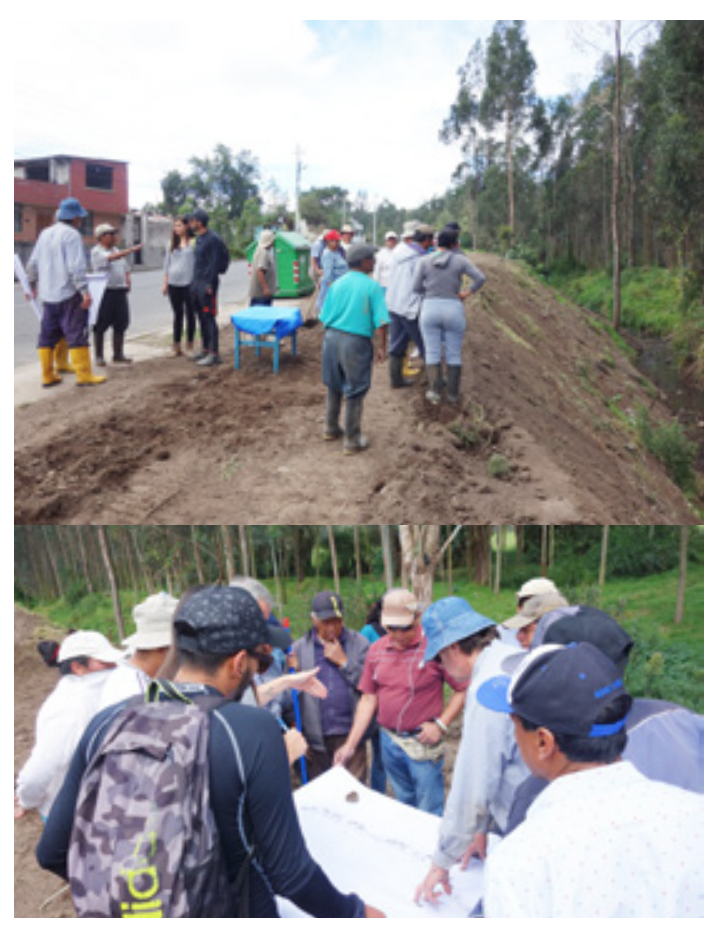

Figura 6 Limpieza y replanteo del espacio a través de la minga comunitaria. Fuente: Fotografías de María Dolores Montaño, 2017 

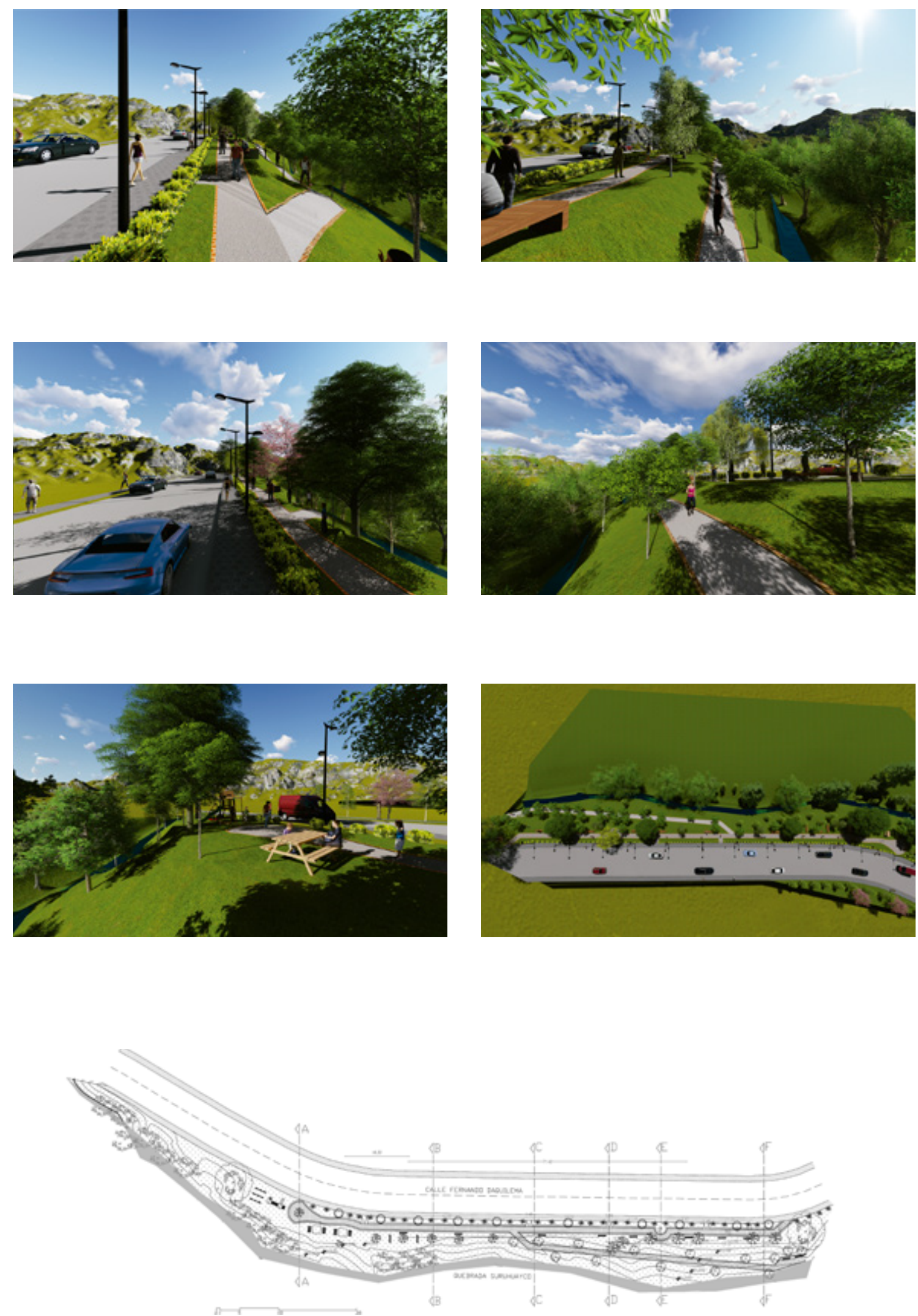

Figura 7 Implantación y perspectivas del proyecto entregado. Fuente: Pamela Guerrón, David Parreño, Alejandro Valarezo y Andrés Ramos, 2017. 


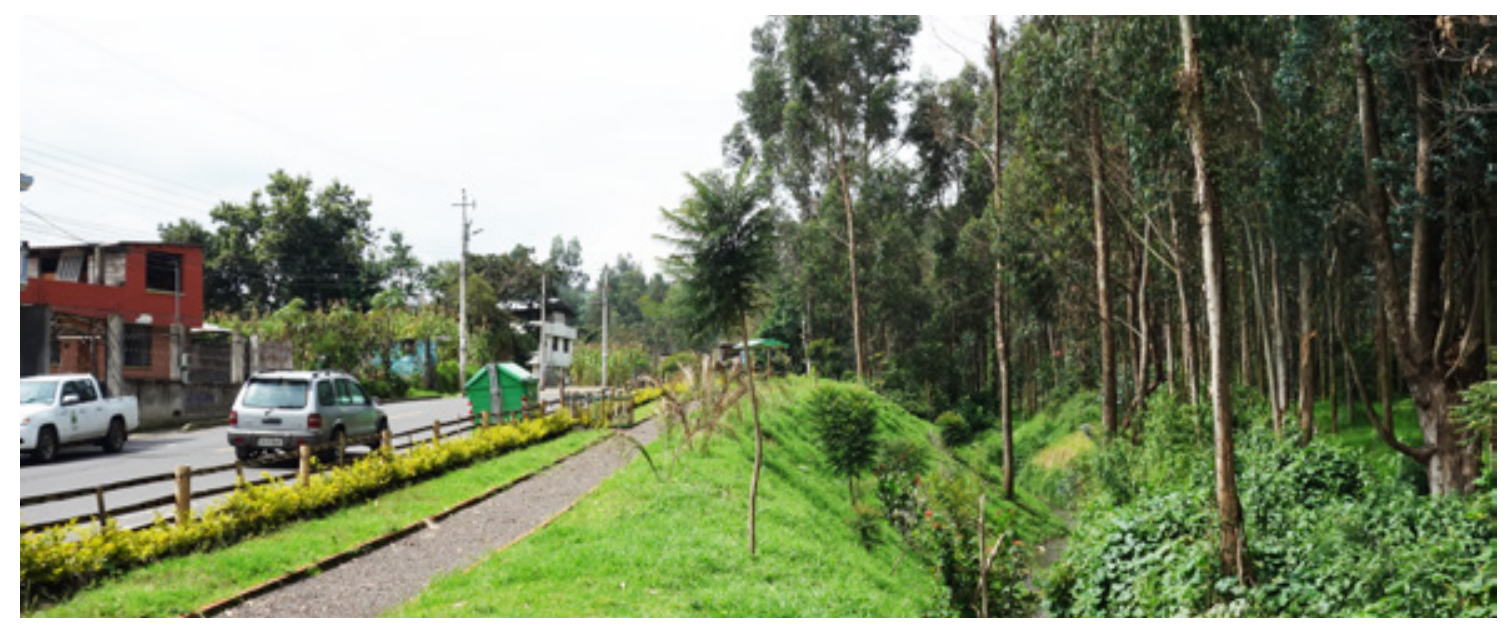

Figura 8 Estado actual. Fuente: Fotografía de María Dolores Montaño, 2018.

El nuevo grupo de la FADA-PUCE, Laboratorio de los Paisajes Vivo realiza una nueva entrega completa de documentos a la presidencia del Gobierno Autónomo Descentralizado ${ }^{8}$-autoridad local- quien, sin embargo, había modificado el proyecto original. El GAD contrató a un profesional para el diseño y la construcción del proyecto, que fue reformado a priori para justificar el uso de una partida presupuestaria.

El equipo académico entrega, entonces, a la comunidad nuevos planos considerando las modificaciones que el profesional contratado por el GAD ha realizado en la quebrada, para no alterar el proceso de continuidad y la inversión y construcción realizada en el sitio.

Le corresponde a la comunidad seguir gestionando las siguientes etapas de rehabilitación de la quebrada en todo el cauce en la que se relaciona y pasa por la parroquia y la concientización de la importancia del tratamiento de sus aguas, bordes, y de convertirla en un lugar de interrelación social, de encuentro comunitario, de integración con el hábitat, de significados como espacio característico de las condiciones territoriales andinas y como puente entre dos mundos.

En la Figura 7 se observa la situación de la quebrada en mayo de 2018.

En adelante, se continúa trabajando con nuevos pedidos de la comunidad en los barrios El Manzano, El Pino, San Carlos de Conejeros entre otros, establecidos a través del convenio entre el $\mathrm{GAD}^{9}$ de la Parroquia rural de Cotogchoa y la PUCE ${ }^{10}$.

\section{RESULTADOS}

El caso de la rehabilitación de la Quebrada Suruhuayco establece múltiples aprendizajes para el laboratorio, la academia y la comunidad. A partir de los tres ejes que estructuran el laboratorio, Docencia, Investigación y Vinculación, se emprendieron acciones para transformar el "paisaje malcriado" en un paisaje vivo sano, lo que se denomina "crianza de los paisajes vivos, uyway".

Las quebradas para el mundo andino se constituyen en puentes cósmicos entre el hanaq pacha ("espacio de arriba"), el kay pacha ("esfera de aquí y ahora") y el mundo de "adentro", de los difuntos y ancestros (uray/ukhu pacha), devolviendo a la Quebrada Suruhuayco su condición de vínculo entre el cosmos, el mundo del presente y el mundo subterráneo de la memoria y los ancestros.

Gracias a las acciones evidenciadas a lo largo del proceso se puede apreciar que la comunidad de Cotogchoa ha recuperado el vínculo relacional con sus espacios públicos representativos, espacios de diálogos, de afectos y de empoderamiento a través de un proceso de diseño participativo en el cual todos interactúan, trabajan y construyen: la academia, la comunidad y el Gobierno Autónomo Descentralizado.

Es importante reflexionar sobre el uso de las prácticas ancestrales $\tan$ características del mundo andino, las que para la comunidad de Cotogchoa constituyen una práctica usual, como lo es el trabajo en minga. Según establecen Alfredo Altamirano y Alberto Bueno Mendoza, en Perú:

[8] El artículo 238 de la Constitución de la República del Ecuador establece que constituyen Gobiernos Autónomos Descentralizados (GAD) las juntas parroquiales rurales, los concejos municipales, los concejos metropolitanos, los consejos provinciales y los consejos regionales, y estos gozan de autonomía política, administrativa y financiera, y se rigen por los principios de solidaridad, subsidiariedad, equidad interterritorial, integración y participación ciudadana. Es decir, son las instituciones que conforman la organización territorial del Estado Ecuatoriano.

[9] Gobierno Autónomo Descentralizado.

[10] Pontificia Universidad Católica del Ecuador. 
Con este sistema [la minga], la colectividad ejecutaba las obras que beneficiaban al ayllu como un todo: canales de irrigación local, andenes (terrazas de cultivo en las faldas de cerros), puentes, templos, ciudades, locales de preparación de charqui y/o almacenamiento de productos, corrales, cercas, manutención de las huacas locales con enterramientos humanos, etc. Este sistema envolvía y obligaba a todos los miembros de la comunidad a trabajar en beneficio de la comunidad o ayllu. Eventualmente, la minga también era realizada cuando ocurría el casamiento de miembros del ayllu (ex. en la construcción de su casa) o en el cuidado de las tierras de huérfanos, inválidos, viudas, enfermos y ancianos del ayllu. (Altamirano, et al. 2011: 54-55).

Las actividades comunitarias, como la minga, son recursos valiosos para la concreción de acciones que logren reducir costos en los proyectos, teniendo en cuenta que son prácticas ancestrales andinas que producen comunicación, conocimiento, afectos, vínculos, diálogos, reciprocidad, solidaridad y relaciones, tanto como el empoderamiento del lugar y del espacio público.

\section{CONCLUSIONES}

Las acciones realizadas en el proyecto de rehabilitación de la Quebrada Suruhuayco son apreciables para la retroalimentación de procesos y actuaciones desde el Laboratorio de los Paisajes Vivos y la PUCE. Permite la utilización de metodologías que consideran los principios andinos como una alternativa válida e incluyente para mejorar un territorio a través de la propia comunidad apoyada por la academia. El principio andino de ciclicidad (hacer, deshacer, rehacer) posibilita un proceso que enriquece la experiencia y que permite acceder desde cualquier etapa.

El testimonio de la recuperación de la quebrada reafirma, comprende, valora, evalúa y rediseña próximas acciones y estrategias con la práctica de este proyecto hacia el emprendimiento de nuevas iniciativas que mejoren la calidad de vida de las comunidades y les dote de espacios de vinculación y diálogo comunitario.

Las acciones conjuntas academia-comunidad enriquecen conceptos, actitudes, acciones, proyectos y trabajos como ejemplo significativos de buenas prácticas a través de la propuesta de metodologías y trabajos que incentiven a la comunidad a que continúe sola en la gestión y construcción de sus paisajes a través de la "crianza de paisajes vivos" (uyway).

Los profesores, investigadores y estudiantes que se integran a este proceso lo hacen a través de la conciencia de que es una acción de reciprocidad-ayni-como aporte basado en el principio andino hacia el apoyo al crecimiento de las comunidades y sus paisajes.

\section{Integrantes del Laboratorio de los Paisajes Vivos FADA PUCE}

Karina Borja, María Dolores Montaño, Renato Ríos, Ekaterina Armijos, Juan Carlos González, Claudia Mora, Christine Van Sluys, estudiantes de Arquitectura FADA-PUCE.

\section{REFERENCIAS BIBLIOGRÁFICAS}

ALTAMIRANO, Alfredo y BUENO, Alberto. El ayni y la minka: dos formas colectivas de trabajo de las sociedades preChavín, Revista de Investigaciones Sociales [en línea], 2011, vol. 15, no 27. [Consultado 4 diciembre 2018]. Disponible en: http:// revistasinvestigacion.unmsm.edu.pe/index.php/sociales/ article/view/7659/6666. p 43-75.

ARMIJOS, Ekaterina; BORJA, Karina; GONZÁLEZ, Juan Carlos; MONTAÑO, María Dolores y RíOS, Renato. El Taller de Arquitectura del Laboratorio de los Paisajes Vivos de la FADAPUCE. Acercamientos y acciones desde la academia hacia la comunidad: Cotogchoa, Ecuador, Revista Cardinalis, 2016, n 6, pp. 114-129. [Consultado 4 diciembre 2018]. Disponible en: $\quad$ https://revistas.unc.edu.ar/index.php/cardi/article/ view/14886/14862.

BAUSELA, Esperanza. La docencia a través de la investigaciónacción, Revista lberoamericana de Educación, 2004, vol. 35, n 1 pp. 1-10. [Consultado 4 diciembre 2018]. Disponible en: https:// rieoei.org/RIE/article/view/2871

BORJA, Karina. Criar paisajes vivos. Una manera de aprehender los paisajes urbanos andinos. El caso de San Isidro de El Inca. Tesis Universidad del País Vasco/EHU, Departamento de Filosofía de los Valores y Antropología Social, San Sebastián, 2011.

BORJA, Karina. Criar paisajes vivos, una manera de aprehendery (re) pensar la ciudad, Cuadernos Vivienda y Urbanismo [en línea], 2016, vol. 9, no 18, pp. 276-291. DOl: https://doi.org/10.11144/ Javeriana.cvu9-18.cpvm

CIFUENTES, María Ángela y BORJA, Karina. Paisajes y memoria viva: Cotogchoa y su patrimonio, en Civitic 2017. En: Memorias del Congreso de Estudios de la Ciudad, volumen 3: Patrimonio. Cuenca, Universidad del Azuay, 2018, pp. 14-24.

ESTERMANN, Josef. Filosofía andina. Sabiduría Indígena para un mundo nuevo. La Paz: Instituto Superior Ecuménico Andino de Teología (ISEAT), 2006

La filosofía quechua, Josef Estermann ¿Pensamiento Quechua o Incaico? [en línea], 2012. [Consultado 4 diciembre 2018]. Disponible en: https://epistemologiasdesdeelsur.files. wordpress.com/2014/04/12-quechua-estermann.pdf.

Laboratorio de los Paisajes Vivos PUCE [en línea]. PUCE, Blogspot, 2017. [Consultado 4 diciembre 2018]. Disponible en: https://www.puce.edu.ec/portal/wr-resource/blobs/1/ LaboratoriodelospaisajesvivosKborja.pdf. Quito.

LEWIN, Kurt. La investigación-acción participativa. Inicios y desarrollos [en línea]. [Consultado 4 diciembre 2018]. Disponible en: https://s3.amazonaws.com/academia.edu documents/35015397/Park.pdf?AWSAccessKeyld=AKIAIW OWYYGZ2Y53UL3A\&Expires $=1545945047 \&$ Signature $=$ YF 3nA1xEDfwmBwetFB0LJ9loaWY\%3D\&response-contentdisposition=inline\%3B\%20filename\%3DPark.pdf.

MONTAÑO, María Dolores. Los Paisajes Interculturales. Análisis, diagnóstico, valoración y planificación para la Ordenación de un territorio.ElcasodeCotogchoa, RepositorioUniversidaddeCuenca [en línea], 2017. [Consultado 4 diciembre 2018]. Disponible en: http://dspace.ucuenca.edu.ec/handle/123456789/28241.

MONTAÑO, María Dolores y ARMIJOS, Ekaterina. La crianza de los Paisajes Vivos como detonante de sus transformaciones. E caso de Cotogchoa, Estoa. Revista de la Facultad de Arquitectura y Urbanismo de la Universidad de Cuenca [en línea], 2018, vol. 7, $\mathrm{n}^{\circ} 12$, pp. 33-47. [Consultado 4 diciembre 2018]. Disponible en: https://publicaciones.ucuenca.edu.ec/ojs/index.php/estoa/ article/view/1558 